DOI: https://doi.org/10.47405/aswj.v5i3.146

\begin{tabular}{|c|}
\hline $\begin{array}{c}\text { Asian Social Work Journal (ASWJ) } \\
\text { ASOCRAAL WORK } \\
\text { (ASW) }\end{array}$ \\
Volume 5, Issue 3, October 2020 \\
e-ISSN : 0128-1577 \\
Journal home page: \\
www.msocialwork.com \\
\hline
\end{tabular}

\title{
Indicators of Effective Social Care Interventions Administered to Looked-After Youths and Children
}

\author{
Amos Magut ${ }^{1}$, Rose Otieno ${ }^{1}$, Godfery Ng'eno $^{2}$ \\ ${ }^{1}$ School of Arts and Social Sciences, Kisii University, Kenya \\ ${ }^{2}$ School of Education, Moi University, Kenya \\ Correspondence: Amos Magut (magut@kisiiuniversity.ac.ke)
}

\begin{abstract}
This study is based on a review of literature on social interventions given to children and the youth in institutional contexts. From the review, the study reports that the efficacy of social interventions may be ascertained by the presence of the following indicators in looked-after children: attachment to caregivers and peers, social connectedness, interpersonal competence, sense of autonomy. Based on these results, the study recommends that institutions of care need to develop a framework for evaluating their social programmes that integrate these indicators. Such an evaluation programme would offer a comprehensive framework for enhancing programme efficiency and continuous improvements of the standards of care given to looked-after youths and children. Despite being based on a review of literature, this study make important suggestions on the most effective ways for helping looked-after youths to cope with life's difficulties now and in the future. The paper may help care homes to provide an environment conducive for social restoration and nurturing of healthy youths and children. This forms an important foundation to the holistic development of youths and their ability to achieve success in school, work, and social interactions. The study also provides useful information to the government, scholars and other child-care stakeholders on the actual effect of the social interventions on development of resilience factors like optimism, active coping, hardiness and purpose in life.
\end{abstract}

Keywords: indicators, effective social care interventions, looked-after youths, children institutional contexts

\section{Introduction}

A number of authors (Better Care Network \& UNICEF, 2015; Save the Children, 2009; UNICEF, 2011; Hunter \& Williamson, 1998) maintain that children need and have a right to be cared for and, grow up with their biological parents in order to grow and develop optimally. Consequently, most governments and international bodies such as the United Nations recognize this fact and strive to ensure orphans and other vulnerable children enjoy the right to grow up with their biological parents or blood relatives. However, experience has shown that millions of children live in out-of-home arrangements around the world owing to various factors (SOS-Kinderdorf International, 2007).

Several factors have contributed to children leaving home. The HIV/AIDS pandemic, poverty and violence are just some of the many challenges and adversities that many children in the sub-Saharan Africa experience (Hunter \& Williamson, 1998; Mburugu et al., 2014). These challenges have brought about death of parents resulting in an overwhelming number of needy orphans across the resource- 
constrained nations. As result, many children are becoming increasingly vulnerable and many are exiting their broken families and communities to fend for themselves on the streets. Others have been taken into refugee camps or in informal kinship or community care, residential care whereas runways are recruited as child combatants, or are trafficked for labour or sexual exploitation (Skovdal, 2009). Those children who are lucky have been taken in by charitable groups who now provide them with care, housing and education. Care modalities for orphans and separated children (looked-after children) are being overstretched owing to enormous challenges posed by this pandemic and other problems in various communities. The situation is dire since, as Thembela (2007) asserts, the vulnerabilities of these children are further compounded by the fact that they are cared for by vulnerable families and reside in equally vulnerable communities.

UNICEF and global partners aver that there were nearly 140 million orphans globally in 2015, including 52 million in Africa. It is estimated that in Kenya there are 2.19 million orphans, and a fragment of this group requires special care and protection. Apart from orphans, other vulnerable children (about 8 million) require help to be able to survive and go to school. The situation for these children is compounded by widespread poverty in the country (which is at $46 \%$ of the population) that continues to subject orphans and vulnerable children to serious deprivation of necessities of life. Poverty, compounded by the upsurge of HIV/AIDS and the weakening community structures, has exposed children to vulnerability that is manifested in food shortage, lack of shelter, lack of medical care, high school drop-out, malnutrition, high mortality rate; and this has worsened the living conditions of this segment of our society (Ministry of Labour and East African Community Affairs, 2017).

Many looked-after children have endured difficult social, physical and psychological experiences. According to Shumba and Moyo (2014), over and above bereavement, many of these children have experienced first-hand severe chronic illness of a parent or caregiver, poverty, hunger, lack of access to services, inadequate clothing or shelter, overcrowding, deficient care, disability, and even physical or sexual violence. These problems have the potential to disrupt a child's growth and development. Therefore, looked-after children need adequate mental health care to guard them from developing abnormalities. Such care can be achieved through provision of targeted psychosocial programming.

\section{Results and Discussion}

The study sought to ascertain the indicators of effective social intervention programmes given to looked-after youths and children in institutional contexts. The study was based on the rationale that human beings are social creatures who dependent on one another. To be healthy, youth in care need to experience a sense of belonging and being connected to others. Caregivers thus need to provide an environment where this flourishes. Social interventions in care home ought to entail putting an emphasis on bringing up a child in a holistic environment where education, care and society are intertwined. The central tenet is building relations that are crucial to promote strong emotional development, based on the importance of attachment theory, having a secure base and developing good social skills. It puts the child or young person at the centre and builds outwards, integrating care and education in its broadest sense to provide a holistic package of support (White \& Davidson, 2006).

According to Petrie (2002), social interventions aims to achieve holistic development, which is seen in acquisition of cognitive knowledge, emotional and spiritual learning, and practical and physical skills. Petrie further points out that it nurtures holistic well-being through strengthening health-sustaining factors and providing support for people to enjoy a long-lasting feeling of happiness. Furthermore, it enables children, young people as well as adults to empower themselves and be self-responsible persons who take responsibility for their society, and finally promote human welfare and prevent or ease social problems

The quality of the social environment in a care home has profound impacts on the human capacity to cope (White\& Davidson, 2006). Supportive relationships with caregivers therefore is vital in sustaining young people through life crises. With the assumption that some stressors can neither be avoided nor modified, interventions which increase available social competencies can facilitate coping 
in the face of effects of past and current challenges. A survey of looked-after youth's literature revealed the following social competencies as key predictors of a youths' social wellbeing in care: Attachments to caregivers/peers, social connectedness, interpersonal sensitivity and sense of autonomy (ACCIK, 2016; International Federation of Red Cross and Red Crescent Societies: Reference Centre for Psychosocial Support, 2009; REPSSI, 2008; Ballew \& Mink, 1986; Ireland Children Acts Advisory Board, 2009; Woodside \& McClam, 1998).

\section{Attachment to Caregivers and Peers}

A key aspect in youth socialisation programming focuses on the attachment of the child and his or her primary care-giver. There must exist the natural, healthy interaction, which should develop between the child and the primary caregiver in care home. The key aspects that are stressed here are: an attitude of positivity and joy (by which caregiver convey to the child that he or she is capable, competent and skilful in doing many things), physical intimacy (by which caregiver stress that he wants to take care of the child and that he or she is worth his attention), being personal (ensuring that the child feels unique and special) and interactivity (conveying that a caregiver can enjoy being and doing things together with the child) (Tuomi \& Tuulet, 2011).

Moreover, sensitivity and responsiveness have been identified as key characteristic of caregiving behaviour related to later positive health and development outcomes in young children (World Health Organization, 2004). Sensitivity can be described as an awareness of the child's acts and vocalizations as communicative signals to indicate needs and wants. Responsiveness is the capacity of caregivers to respond appropriately to the child's signals. To ensure the child's health and growth in care homes, caregivers need to be sensitive to the physical state of the young child, to be able to judge and respond to child's need in an appropriate manner. They can be able to make these judgements because they monitor the child's movements, expressions, colour, temperature, and the like.

\section{Social Connectedness}

Social connectedness refers to the person's subjective awareness of being in close relationship with the social world and environment as a whole. According to Lee, Draper and Lee (2001), social connectedness an attribute of the self, that reflects cognitions of enduring interpersonal closeness with the social word. Lack of social connectedness instead indicates a difficulty in relationship with the social world. Social connections provide look after children with source of emotional support, material help, and information they need to thrive. Social connectedness - both the sum of individual relationships and a sense of belonging - is crucial to overall health and wellbeing of children in care homes (ACCIK, 2016).

Research by Lee et al. (2014) shows how low socially connected people experience discomfort in social situations, feeling their self-misunderstood or isolated, unsatisfied of their relationships. Further, this research confirms that the widespread social and relational difficulties experienced by those with low social connectedness may contribute to more general psychological distress. Authors like Twenge, Catanese and Baumeister (2002) report that when children feel excluded from meaningful social relationships, they pursue pleasurable activities (including those of high-risk) and engage in fewer health-enhancing behaviours, despite any unfavourable long-term consequences.

There are several factors that may reinforce social connectedness among young people living together. These include: staying in an environment free of pervasive societal stigma and discrimination; provision of clear responsibility within routines or tasks for promoting vocational and social outcomes for the youth; provision of ongoing vocational support for the youth; and finally removal of barriers to community engagement - e.g. providing education, arts, sports and leisure services by making these services more accessible for the youth in care (Tan, 2004). 


\section{Interpersonal Competence}

Interpersonal competence focuses on a person's ability to interact with others and with the greater community (Northwestern University, 2016). Competence in this domain includes the ability to foster and maintain healthy, mutually beneficial relationships with others, and the capacity for interdependence and collaboration. The Northwestern University proposes three key areas of interpersonal functioning, which need to work optimally for youth wellbeing to be realized. First, they assert that an aspect of leadership is key in interpersonal relationship. The indicators for this include: seeking and considering feedback from others; exhibition of sensitivity and understanding of others' perspectives in a respectful manner; maintenance of healthy, mutually beneficial relationships with others; effectiveness in weaving and analysing information from multiple sources and perspectives into a cohesive narrative; employing narrative to engage people and call them to action; acting in congruence with personal, organizational and community values and beliefs and finally demonstrating leadership through role modelling, influence, and service.

The second aspect of interpersonal competence among youth is civic engagement. Youth who are fully competent in this area: Demonstrates the ability to work with people of different genders, sexual orientations, races/ethnicities, nations, religions, socioeconomic statuses; Exhibits the ability to connect with others across communities; adapt behaviours appropriately to live and work in an evolving, diverse world; and finally demonstrates care and concern for the welfare of others. The third and final aspect interpersonal competence among youth is interdependence. Youths who have acquired this competence; Accepts responsibility for actions; Works collaboratively with others; recognizes how one's personal actions affect other people and communities, and constructively resolves interpersonal conflicts.

An ability to engage in interpersonal relationships in various social situations is known to be important for healthy adjustment in society and psychological well-being for the youth. This, according to Changdai et al. (2008) is attributed to the findings that the ability to engage in close relationships and to be liked by others is correlated to indices of functioning such as self-worth, education, psychological distress, criminal behaviour, and ego development. Interpersonally competent youth, therefore, understand themselves, and may use this self-awareness to better understand others. Besides becoming self-aware, they also build and nurture mutually beneficial relationships with the people in their life. Moreover, they get to know how to resolve conflict in a positive manner. The relationships the youth establish and maintain may be used as a means to get help from others during crisis situations.

\section{Sense of Autonomy}

When autonomous, people experience their behaviour as self-endorsed and congruent with their values and interests (Weinstein et al., 2012). The first manifestation of autonomy is when an individual experiences him or herself as the author of behaviour, and fully assents to the actions he or she undertakes. The second aspect is interest-taking, which is a spontaneous tendency to openly reflect on inner and outer events. Interest-taking facilitates awareness and ongoing insight into oneself and one's experiences, which in turn is important for the high level of self-governing involved in autonomy. It involves a motivated attention in which one is receptive to both positive experiences and those that might seem threatening. The autonomous individual is therefore engaged in a continuing process of learning more about him or herself (Ryan \& Deci, 2006). The third and final trajectory of autonomy is the absence of external and internal pressure as motivators for behaving. Individuals who are dispositionally low in autonomy should perceive a lesser degree of personal choice and initiative in situations, and instead see behaviour as a response to pressure from others' expectations or from introjected pressures and self-imposed "have to's" (Weinstein et al., 2012). All the all three characteristics (i.e., authorship/congruence, interest-taking, and non-susceptibility to being controlled) are central to sense of autonomy.

There is an assertion that suggests that the extent to which behaviour is autonomous and regulated by the self rather than by external contingencies, predicts a variety of positively experienced actions and 
behaviours (Ryan \& Deci, 2006). According to Weinstein et al. (2012), behaviour that is more autonomous has been associated with more creative learning and engagement, greater energy, lower stress and higher well-being, and more rewarding socialization among other positive outcomes. One of the ultimate goal of caring looked-after youth is to foster their sense of autonomy so that they can grow to become responsible, successful and productive members of society. Consequently, caregivers need to nurture their growing autonomy through positive psychosocial care strategies. According to Maccoby and Martin (1983), such strategies has two important components: (1) providing children with developmentally appropriate opportunities to make choices, and (2) allowing them to experience the consequences of those choices. This lead to growth of sense of autonomy as demonstrated by their age-appropriate independence, ability to get about in the environment and demonstration of ageappropriate responsibility for self.

It is perceptible from the above that attainment of autonomy by young people can be achieved through teaching them independent living skills throughout their stay in care homes and as their abilities develop. This is accomplished through teaching them basic domestic skills that are essential to their eventual ability to live independently. Other strategies include letting them prepare meals, do laundry work, tidy up their room, feed oneself and make or plan nutritious food choices all of which are essential to healthy, independent living. Moreover, they need to be versed with safety issues, as this is critical to the well-being of anyone who lives independently. Consequently, they need to understand safety measures and precautions in all places they spend their time in. It is apparent, therefore, that providing opportunities for children to practice responsibility encourages them to be more autonomous.

\section{Conclusion}

Social interventions administered to looked-after youths and children may be measured using the following indicators: The presence of a sense of attachment to caregivers and peers, social connectedness, interpersonal competence, sense of autonomy.

Regarding the attachment to caregivers and peers, the study found that there must exist the natural, healthy interaction, which should develop between the child and the primary caregiver in care home. The key aspects stressed in this indicator are: an attitude of positivity and joy (by which caregiver convey to the child that he or she is capable, competent and skilful in doing many things), physical intimacy (by which caregiver stress that he wants to take care of the child and that he or she is worth his attention), being personal (ensuring that the child feels unique and special) and interactivity (conveying that a caregiver can enjoy being and doing things together with the child).

Social connectedness refers to the person's subjective awareness of being in close relationship with the social world and environment as a whole. Social connections provide look after children with source of emotional support, material help, and information they need to thrive. Moreover, interpersonal competence focuses on a person's ability to interact with others and with the greater community. Competence in this domain includes the ability to foster and maintain healthy, mutually beneficial relationships with others, and the capacity for interdependence and collaboration.

Lastly, the first manifestation of autonomy is when an individual experiences him or herself as the author of behaviour, and fully assents to the actions he or she undertakes. The second aspect is interest-taking, which is a spontaneous tendency to openly reflect on inner and outer events. Interesttaking facilitates awareness and ongoing insight into oneself and one's experiences, which in turn is important for the high level of self-governing involved in autonomy. It involves a motivated attention in which one is receptive to both positive experiences and those that might seem threatening.

It is important to measure all these indicators simultaneously to provide a comprehensive feedback on the effectiveness of programmes and what needs to be improved. Therefore, institutions of care need to develop frameworks for evaluating their social programmes that integrate these indicators. Such an 
evaluation programme would offer a comprehensive framework for enhancing programme efficiency and continuous improvements of the standards of care given to looked-after youths and children.

\section{References}

Association of Charitable Children Institutions of Kenya (2016). Manual for Charitable Children's Institutions in Kenya. Nairobi: ACCIK.

Ballew, J. R., \& Mink, G. (1986). Case Management in the Human Services. Charles C. Thomas Publisher, Limited.

Better Care Network \& UNICEF (2015). Making Decisions for the Better Care of Children: The role of gate-keeping in strengthening family-based care and reforming alternative care systems. Better Care Network \& UNICEF.

Changdai, K., Min, S., Yune, C., \& Eun, G. (2008). Employees' Perceptions of Interpersonal Competence: The Case of South Korea. Asian Pasic Education Review, 9(2), 221-232.

Hunter, S., \& Williamson, J. (1998). Discussion Papers on HIV/AIDS Care and Support: Responding the Needs of Children Orphaned by HIVIAIDS. Arlington: Health Technical Services (HTS) Project.

International Federation of Red Cross and Red Crescent Societies: Reference Centre for Psychosocial Support (2009). A Handbook - Psychosocial interventions. Copenhagen.

Ireland Children Acts Advisory Board (2009). Best Practice Guidelines for the Use and Implementation of Therapeutic Interventions for Children and Young People in Out of Home Care. Belfast: Ireland Children Acts Advisory Board.

Lee, M., Draper, M., \& Lee, S. (2001). Social connectedness, dysfunctional interpersonal behaviours, and psychological distress: testing a mediator model. J Couns Psychol, 48, 310-8.

Lee, V. C., Muriithi, P., Gilbert-Nandra, U., Kim, A. A., Schmitz, M. E., Odek, J., ... for the KAIS Study Group (2014). Orphans and Vulnerable Children in Kenya: Results from a Nationally Representative Population-Based Survey. Journal of Acquired Immune Deficiency Syndromes (1999), 66(Suppl 1), S89-S97.

Maccoby, E. E., \& Martin, J. A. (1983). Socialization in the context of the family: Parent-child interaction. In P. H. Mussen, (Ed.), Handbook of child psychology, Vol IV (pp. 1 - 101). New York: John Wiley and Sons.

Mburugu, P. M., Muiruri, P., Opiyo, N., Theresa, O., Osingada, C. P., Ngabirano, T. D., \& Gachuno, O. (2016). Treatment outcomes of HIV infected adolescents attending a national referral hospital in Kenya. Annals of Global Health, 82(3), 513-514.

Ministry of Labour and East African Community Affairs, 2017

Northwestern University (2016). Learning Domain - Interpersonal Competence. Retrieved from http://www.northwestern.edu/studentaffairs/assessment/learning-outcomes/student-learningoutcomes/interpersonal-competence/index.html

Petrie, P. (2002). Social pedagogy: An historical account of care and education as social control. In J. Brannen \& P. Moss (Eds.), Rethinking Children's Care. Buckingham: Open University Press

Regional Psychosocial Support Initiative (REPSSI) (2008). Mainstreaming Psychosocial Care and Support - A Manual for Facilitators. REPSSI.

Ryan, R. M., \& Deci, E. L. (2006). Self-regulation and the problem of human autonomy: Does psychology need choice, self-determination, and will? Journal of Personality, 74, 1557-1586.

Save the Children (2009). Institutional Care - The Last Resort. Save the Children.

Shumba, J., \& Moyo, G. (2014). Counselling needs of orphaned children: A case study of Harare metropolitan children. Mediterr J Soc Sci., 5(11), 145.

Skovdal, M. (2009). Young Carers in Western Kenya Collective struggles and coping strategies (Unpublished PhD thesis). Institute of Social Psychology of the London School of Economics and Political Science, London.

SOS-Kinderdorf International (2007). Children without parental care or at risk of losing it. Position Paper of SOS-Kinderdorf International. Retrieved March 10, 2018 from http://www.europarl.europa.eu/hearings/20070417/libe/sos_children_en.pdf 
DOI: https://doi.org/10.47405/aswj.v5i3.146

Thembela, L. (2007). An Evaluation Of A Psychosocial Support Intervention For Vulnerable Children (Unpublished $\mathrm{PhD}$ thesis). University of Zululand.

Tuomi, K., \& Tuulet, P. (2011). Supporting Interaction in the Context of Residential Child Care. Scottish Journal of Residential Child Care, 10(1).

Twenge, J. M., Catanese, K. R., \& Baumeister, R. F. (2002). Social exclusion causes self-defeating behaviour. Journal of Personality and Social Psychology, 83, 606-615.

UNICEF (2011). Children in Informal Alternative Care. New York: UNICEF.

Weinstein, N., Przybylski, A., \& Ryan, R. (2012). The index of autonomous functioning: Development of a scale of human autonomy. Journal of Research in Personality, 46(2012) 397413.

White, W., \& Davidson, L. (2006). Recovery: The Bridge to Integration? Behavioural Healthcare, 26(11), 22-25.

Woodside, M., \& McClam, T. (1998). Generalist Case Management: A method of Human Service Delivery. Pacific Grove: Brooks/Cole Publishing Company.

World Health Organization (2004). The Importance of Caregiver-Child Interactions for the Survival and Healthy Development of Young Children: A Review. Geneva: WHO. 